\title{
LA RIADA DEL TURIA DE 1731. UNA APROXIMACIÓNA LA LITERATURA DE LA CATÁSTROFE
}

\author{
Alfredo Faus Prieto \\ Departamento de Geografía. Universidad de Valencia \\ alfredo.faus@uv.es
}

\section{RESUMEN}

Los sucesos naturales de carácter extraordinario que se han sucedido a lo largo de la historia han dejado tras de sí un gran legado documental. Fenómenos como los terremotos, las erupciones volcánicas, las sequías, las plagas, etc. han constituido desde siempre un motivo de preocupación para las poblaciones expuestas y una ocasión para desatar la imaginación de los cronistas. En el caso de la ciudad de Valencia, ningún fenómeno natural ha influido tanto en su historia como las avenidas recurrentes del río Turia. Una de ellas, la riada extraordinaria de septiembre de 1731, quedó registrada en documentos de todo tipo que pueden englobarse bajo la denominación común de literatura de la catástrofe. En este artículo se analizan cuatro relaciones impresas del suceso y dos dietarios personales manuscritos, en un intento de ampliar los datos conocidos del desastre y, sobre todo, de enmarcarlo en el contexto social y político en el que tuvo lugar.

Palabras clave: Ciudad de Valencia, río Turia, riada, 1731, literatura de la catástrofe.

\section{ABSTRACT}

The flood of the Turia River of 1731. An approximation to the literature of the catastrophe

The natural events of extraordinary character that have happened along the history have stopped besides yes a great documentary legacy. Phenomena like the earthquakes, the volcanic eruptions, the droughts, the plagues, etc. they have constituted from always a motive of worry for the exposed populations and an occasion to untie the imagination of the chroniclers. In case of the city of Valencia, no natural phenomenon has influenced so much his history as the avenues appellants of the river Turia. One of them, the extraordinary flood of September, 1731, remained registered in documents of all kinds that can be included under the common name of literature of the catastrophe. In this article there are analyzed four printed relations of the event and two personal manuscript record-books, in an attempt of extending the information known about the disaster and, especially, of framing it in the social and political context in which it took place.

Keywords: City of Valencia, Turia river, flood, 1731, literature of the catastrophe

\section{INTRODUCCIÓN}

El domingo 16 de septiembre de 1731 la ciudad de Valencia sufrió una gran inundación provocada por el enésimo desbordamiento histórico del río Turia (Pérez y Faus, 1990). Tras dos días de fuertes lluvias centradas sobre el llano de Quart y las estribaciones montañosas que lo delimitan, el frente del agua alcanzó el casco urbano cogiendo completamente desprevenidos a sus habitantes ya que apenas había llovido sobre él la noche antecedente y no se había apreciado un aumento significativo en el nivel del río hasta ese momento. Sus efectos fueron, no obstante, muy diferentes en las zonas situadas intramuros y extramuros debido, básicamente, al estado en el que se encontraban las obras de construcción de los pretiles del cauce. Mientras que en 1729 ya se habían completado las defensas entre la cruz de Mislata y 
la ermita vieja de Monteolivet en el margen derecho del río colindante con el circuito amurallado de la ciudad, las del margen izquierdo no se terminaron hasta 1789 y sólo en el tramo comprendido entre los puentes de San José y del Mar (Melió, 1991).

En consecuencia, en el interior del casco urbano apenas se inundaron las zonas cercanas a los portales de San José, de los Serranos, del Cid y, sobre todo, del Real. En la vaguada próxima a estos dos últimos sufrieron la riada con especial virulencia la Casa de Armas y los conventos de Santo Domingo y de Nuestra Señora del Remedio. En los barrios vecinos de Roters, Blanqueries y la Xerea, la ruptura de algunas acequias que quedaron por debajo del nivel del río y el anegamiento de los pozos provocaron la formación de grandes bolsas de agua, lo que obligó a retirar las rejas que obstruían los albañales y a abrir boquetes de desagüe en los sectores próximos del lienzo de la muralla y de la barbacana del cauce. Por contra, en el margen izquierdo, situado extramuros, la destrucción fue absoluta. La huerta de Campanar, completamente desprotegida, fue la primera en sufrir los embates del agua. A continuación, fueron anegados el llano de la Zaidía, los caminos de Morvedre y Alboraia, la Alameda, el camino del Grau y el núcleo de la Vilanova. Los efectos de la crecida se multiplicaron a partir del puente de San José al unirse su frente con las aguas que arruinaron y desbordaron los pretiles río abajo, una vez que la carga material arrastrada taponó los ojos de los puentes y provocó la colmatación del cauce artificial.

Hasta ahora, estas noticias nos eran conocidas gracias a la Valencia Antigua y Moderna del padre José Teixidor, una obra que había permanecido manuscrita desde 1767 y que fue llevada finalmente a la imprenta en 1895. En ella, este ilustre dominico, bibliotecario del Real Convento de Predicadores de Valencia, le dedicó dos capítulos a las inundaciones históricas del río Turia. En el caso de la ocurrida en 1731, Teixidor reconocía expresamente su deuda con la Historia manuscrita de su correligionario Tomás Güell y emplazaba al lector interesado a acudir al texto original en busca de mayores datos (1895: I, 47-49). Su crónica, que no dejaba de ser un resumen sucinto de la escrita por Güell, se convertiría en un referente obligado para historiadores como Vicente Boix (1845), Manuel Carboneres (1873), Constantino Llombart (1887) y Francisco Almela (1957), que la reprodujeron sin el menor pudor. Como resultado final de este proceso, la información disponible de la riada de 1731 provenía de la copia reiterada del resumen de unas memorias manuscritas que, a su vez, estaban basadas parcialmente en las notas tomadas por Güell de las relaciones publicadas de manera inmediata al suceso.

Este ejemplo es una muestra de cómo un cúmulo de informaciones centradas en un hecho concreto acaba decantándose y llega hasta nosotros filtrado por personas interpuestas. La lectura de las fuentes originales tiene, en este sentido, la virtud y el efecto reparador de ampliar la perspectiva desde la que puede abordarse el hecho en cuestión. En el caso que nos ocupa, la literatura generada por la catástrofe de 1731 que hemos podido reunir, compuesta por cuatro relaciones impresas y dos dietarios manuscritos, proporciona una información que sobrepasa la mera crónica lineal del avance destructivo de las aguas. Las páginas que siguen son una primera aproximación a este tipo de literatura, hecha desde el convencimiento de que la comprensión de los fenómenos naturales no puede abordarse por completo, desde una perspectiva histórica, sin atender al modo en que afectaban a las poblaciones humanas y eran percibidos por éstas.

\section{RELACIONES DE SUCESOS Y LITERATURA MEMORIALÍSTICA}

Los acontecimientos naturales de carácter extraordinario constituyen una fuente inagotable de documentación histórica. Los numerosos documentos generados por tales hechos pueden incluirse, dejando al margen las actas, las visuras y los informes técnicos de carácter institucional, en dos subtipos literarios ya consolidados: las relaciones de sucesos y la literatura memorialística. El primero de ellos constituye un género pre-periodístico interesado por la trascendencia pública de la tragedia, mientras que el segundo engloba a todo tipo de notas, memorias y dietarios personales. Como puede suponerse, estos subgéneros de la literatura catastrófica o de la catástrofe presentan una misma realidad bajo prismas diferentes y con formas literarias diversas. Se trata de las dos visiones, complementarias y divergentes, de un mismo hecho; de las dos caras, familiares y opuestas, de una misma moneda. A un lado y al otro, el acto extrovertido y el acto introspectivo, la inmediatez notoria y la reflexión personal, la noticia que circula y el recuerdo privado. Aunque esta imagen no deja de ser arquetípica y ha de matizarse, a nuestros efectos resulta sumamente útil y funcional.

Las relaciones de sucesos son impresos breves y no periódicos que tienen como rasgos definitorios su intención informativa, centrada en un acontecimiento de base real o ilusoria que conmueve al lector, 
la anonimia generalizada, una narración retórica en la que el autor incluye elementos autobiográficos como fórmula de verosimilitud y un formato muy concreto determinado por la necesidad de abaratar los costes de edición (Infantes, 1996). Su estudio en España puede remontarse a los trabajos pioneros sobre la literatura de cordel de Julio Caro (1969) y María Cruz García (1973) y se ha consolidado gracias a las aportaciones de una larga lista de investigadores encabezada por Víctor Infantes, Agustín Redondo y Henry Ettinghausen. En 1994 comenzó a funcionar en la Universidad de La Coruña, bajo la dirección de Sagrario López, el Seminario Interdisciplinar para el estudio de la Literatura Áurea Española (SIELAE) y, siguiendo su estela, en 1998 se creó la Sociedad Internacional para el Estudio de las Relaciones de Sucesos (SIERS). Además de la organización periódica de coloquios internacionales ${ }^{1}$ y de la publicación anual de boletines informativos (BORESU), esta plataforma ha creado el Catálogo y Biblioteca Digital de Relaciones de Sucesos (siglos XVI-XVIII) y se ha encargado del apartado correspondiente de la Biblioteca Digital del Siglo de Oro (BIDISO). En los últimos años, estas iniciativas han sido completadas por otras, también accesibles en internet, como la exposición digital titulada Relaciones de Sucesos en la BUS (Biblioteca de la Universidad de Sevilla).

La literatura memorialística, por su parte, se caracteriza por la privacidad de la escritura, la autocensura ante lectores no deseados, el reflejo de un conjunto misceláneo de hechos de actualidad vividos por el autor, la intención de dejar memoria de los mismos y el empleo de una gran variedad de formatos (Escartí, 1998). Frente al despliegue anterior, el estudio específico de este subgénero se ha consolidado con un cierto retraso en España. En la actualidad, los centros de investigación más dinámicos se encuentran en la Universidad de Alcalá y en la Universidad Autónoma de Barcelona. En la primera se formó en 2004 el Seminario Interdisciplinar de Estudios sobre Cultura Escrita (LEA-SIECE). Este seminario, dirigido por Antonio Castillo, publica memorias anuales de investigación, edita la revista Cultura Escrita \& Sociedad y organiza regularmente coloquios, simposios y cursos de verano. ${ }^{2}$ Por su parte, en el Departamento de Historia Moderna y Contemporánea de la segunda se constituyó en 2009 el Grup de Recerca d'Història Moderna Manuscrits, bajo la coordinación de Antoni Simó y la participación destacada de Ignasi Fernàndez. Este grupo ha puesto en marcha el proyecto Memòria personal con la intención de digitalizar el mayor número posible de egodocumentos y se ha hecho cargo de la revista Manuscrits, creada en 1985. ${ }^{3}$ Mención aparte merecen, por último, los trabajos de los profesores de la Universidad de Valencia Eulàlia Miralles, María Luz Mandingorra y Josep Vicent Escartí.

Complemento necesario del trabajo de archivo, la literatura de la catástrofe no sólo ha permitido ampliar los datos disponibles sobre las tragedias objeto de estudio (datación, evaluación de daños, medidas adoptadas, etc.), sino que también ha aportado una nueva perspectiva, próxima a la historia de las mentalidades. No se trata ya únicamente de narrar lo ocurrido, sino de indagar cómo se percibía y cómo se transmitía lo ocurrido. La religiosidad popular latente o explícita, el control ideológico sobreimpuesto o la manipulación interesada de los hechos, son aspectos que no pueden soslayarse en favor de la mera crónica lineal del suceso. De este modo, el acercamiento a fenómenos recurrentes como los terremotos, el volcanismo, las heladas, las sequías, las avenidas de agua, etc. cobra una nueva dimensión y coadyuva en el entendimiento de los mecanismos políticos y sociales que hacían comprensibles y aceptables los designios de la naturaleza. El estudio de las estrategias narrativas seguidas en este tipo de textos también puede ayudarnos a entender la amplitud social de su recepción y la larga pervivencia de su contenido. Sobre todo porque, más allá de sus diferencias estilísticas, las relaciones de sucesos y las memorias manuscritas, hijas de un mismo tiempo, coinciden en el discurso de fondo (Bégrand, 2003).

En el antiguo reino de Valencia, ningún fenómeno natural ha dejado un poso literario tan importante como las periódicas avenidas de agua provocadas por sus ríos y ramblas. En el caso del río Turia y de la ciudad de Valencia, con más motivo puesto que nos encontramos ante la mayor aglomeración humana y el centro político del reino, y ante un ejemplo excepcional de la búsqueda de soluciones técnicas a un problema endémico (Almela, 1957). Las grandes riadas de 1358 y 1589 dieron lugar a la creación, respectivamente, de la Fàbrica vella de Murs i Valls y la Fàbrica nova dita del Riu, instituciones que pasaron a

1 El I Coloquio se celebró en Alcalá de Henares en junio de 1995 y el último de ellos (el VII) en Gerona en septiembre de 2014 . Para 2016 está prevista la celebración del VIII coloquio en Trento (Italia). De los seis primeros coloquios existen actas publicadas.

2 El último Coloquio Internacional organizado por el grupo LEA-SIECE, titulado Escribir y archivar los egodocumentos, tuvo lugar en junio de 2013 en la Universidad de Alcalá.

3 Entre las actividades desarrolladas por este grupo merece destacarse la organización del congreso internacional titulado Construcció i projecció de la memòria personal a l'Europa moderna (Institut d'Estudis Catalans, Barcelona, noviembre de 2011). 
encargarse de las obras de encauzamiento del río a su paso por la ciudad. Esta estructura administrativa generó a lo largo del tiempo una importantísima documentación que se encuentra depositada actualmente en el Archivo Histórico Municipal de Valencia. Visuras e informes periciales, proyectos de obras, libros de contabilidad, visitas generales del río, etc. se acumulan en expedientes y legajos. Explotada esta documentación con motivo de las riadas de 1776 (Faus, 1999), nuestra mirada se vuelve ahora hacia ese otro tipo de literatura, más emocional, que le acompañaba y le sobrepasaba en repercusión popular.

\section{LA LITERATURA DE LA CATÁSTROFE}

El estudio de la literatura de la catástrofe en España ha alcanzado un gran desarrollo entre los lingüistas y los historiadores del periodismo, pero no ha ocurrido lo mismo en el caso de otros colectivos. En el ámbito valenciano, por ejemplo, los únicos trabajos reseñables al respecto firmados por historiadores y/o geógrafos son los realizados, dentro de un programa muy ambicioso centrado en la variabilidad histórica del clima, por el grupo de investigadores de la Universidad de Alicante que encabeza Armando Alberola (1999; 2009a; 2009b; 2010). De otro lado, en el apartado específico de la literatura dedicada a las avenidas de agua la atención de los estudiosos se ha dirigido casi en exclusiva hacia el relato de las provocadas por el río Guadalquivir a su paso por la ciudad de Sevilla (Soons, 1992; Bernal y Espejo, 2003; Iglesias, 2013). Por ambos motivos, la existencia de varias relaciones de la riada del Turia de 1731 y de dos entradas referidas a la misma en dietarios coetáneos a los hechos, supone una doble oportunidad para incorporarnos a una línea de investigación en crecimiento y para ampliar el marco geográfico de referencia. Salvando las distancias, se trataría de la misma inquietud que nos llevó, hace tiempo, a interesarnos por los terremotos valencianos de 1748 (Faus, 1988).

\subsection{Tres romances curiosos}

De la riada de 1731 hemos podido localizar, hasta el momento, tres relaciones en forma de romance que aquí citaremos, de manera abreviada, como Verdadero Resumen, Verdadera Relación y Segunda Relación. Las dos primeras se encuentran actualmente en el fondo antiguo de la Biblioteca Valenciana (el Verdadero Resumen formaba parte de la colección de Nicolau Primitiu que le dio origen), pudiendo accederse directamente a ellas a través de su catálogo digital (BIVALDI). La última, en cambio, está depositada en la Biblioteca Histórica de la Universidad de Valencia, adonde llegó, procedente de la librería del convento que los Padres Capuchinos tenían en la ciudad, como resultado de la exclaustración y la desamortización eclesiásticas de 1835-1837.

\subsubsection{Autoría y datación}

Una de las principales características de las relaciones de sucesos es la anonimia, rasgo que se ha tratado de justificar haciendo hincapié en que sus artífices constituían una caterva de escritores de segunda o tercera fila formada por estudiantes, sirvientes, poetas menores, letrados, clérigos de bajo rango, etc. En nuestro caso, esta característica se cumple plenamente, ya que los tres romances que vamos a analizar carecen de firma. No obstante, algo hemos podido averiguar sobre los autores de dos de ellos. De un lado, los catálogos bibliográficos mejor documentados (los de Palau Dulcet, Maffei y Rúa, Aguilar Piñal, López Terrada, etc.) vienen otorgando la autoría del Verdadero Resumen a Pascual Vergadà (Bergadà, Bergara), caballero del hábito de la orden de Nuestra Señora de Montesa que, en calidad de poeta, se ocultaba tras el pseudónimo de Ruiz de Corella (Valencia, 1702-1779). Especializado en la redacción de villancicos, tarea en la que se ocupó de forma casi ininterrumpida entre 1748 y 1773, y de poesías festivas y encomiásticas en lengua castellana, entre sus obras destacan, además del Verdadero Resumen, el romance titulado Breve descripción de la ingeniosa Naumaquia, El entremés nuevo de Ciega, y el sainete Crítica discreta, y el Crítico socarrón (Pastor, 1830: II, 89-90). Por su parte, el autor de la Verdadera Relación se refiere a la esposa del capitán general de Valencia, doña Catalina de Gravina, como "mi Señora la Princesa", lo que da a entender que formaba parte del servicio del palacio del Real (1731: 5).

Respecto de la datación, sabemos que al menos dos de los tres romances fueron escritos en la semana inmediatamente posterior a la tragedia. Así se deduce de la correspondencia que mantuvo Gregorio Mayans desde Madrid, donde residía en calidad de Bibliotecario Real, con algunos de los prohombres de la ciudad de Valencia. El 25 de septiembre, pasados sólo nueve días desde la riada, Blas Jover, su alcalde mayor, le enviaba por correo al erudito de Oliva lo que calificaba como dos "romanzotes groseros" (el Ver- 
dadero Resumen y la Verdadera Relación, según todos los indicios) para informarle de lo ocurrido con cierto detalle. ${ }^{4} \mathrm{Y}$ al día siguiente, el impresor Antonio Bordázar también le remitía, por vía interpuesta, el poema de Vergadà que había recibido de Jover para que lo enmendase y mejorase. ${ }^{5}$ De la inmediatez con la que se escribía este tipo de obras da idea el hecho de que el propio Bordázar atendiera este encargo, bajo el título de Puntual Relación, "al trote" y en apenas "cinco horas". El 2 de octubre se excusaba ante su admirado Mayans por los defectos que hubiera podido observar en esta obra y los justificaba por la premura empleada en su redacción. ${ }^{6}$ Por último, el contenido de la Segunda Relación, así como su título, invitan a pensar que este romance pudo escribirse con posterioridad a los dos restantes, como luego intentaremos precisar.

\subsubsection{Datos de imprenta}

La Verdadera Relación es el único de estos romances en el que consta el lugar de impresión. Fue llevado a la imprenta en el pequeño taller que José García (menor) tenía en la plaza de Calatrava de Valencia, tras haberlo heredado de su padre (de igual nombre y apellido) en 1725. La obra tipográfica de este impresor, avecindado en la parroquia de San Andrés, se extiende hasta 1765 pero presenta un paréntesis entre 1741 y 1746 provocado por la pena de destierro a la que fue condenado tras ser acusado de santero y haber estado encerrado en las cárceles de San Narciso y de las torres de Serranos por publicar falsas indulgencias, jubileos, cartas de hermandad y recibos de misas sin permiso del Comisario General de Cruzada (Serrano, 1898-1899: 184-189). ${ }^{7}$ Quizá porque no se trataba de una obra menor en la producción tipográfica de este taller, esta relación también se singulariza de las otras dos por el hecho inhabitual de tener una portada independiente del texto. Es en ella donde se incluye, además del título enmarcado en orla tipográfica, el pie de imprenta con el nombre del impresor y la dirección de su oficina (Impresso en Valencia, en la Imprenta de Joseph Garcia, en la plaza de Calatrava). ${ }^{8}$

Como sucede con el Verdadero Resumen y la Segunda Relación, lo habitual era que las relaciones de sucesos sólo tuvieran portadillas con el título destacado en letras de grado mayor en la parte superior de la página, seguido del inicio del texto propiamente dicho. La inclusión de imágenes era inusual a causa del alto coste de los grabados y, en las contadas ocasiones en las que sucedía, solía ser el resultado de la reutilización de tacos xilográficos muy gastados. En este sentido, el grabado con la imagen de Nuestra Señora de los Desamparados que preside la primera página de la Segunda Relación constituye una rara excepción. Aunque la iconografía se corresponde (algo que no siempre ocurría) con el contenido de un poema en el que se atribuye a la virgen la salvación de la ciudad durante la riada, su limitada calidad nos hace pensar que estamos ante un grabado que no fue realizado exprofeso para esta edición. En él, apenas se pueden distinguir los atributos simbólicos de la patrona de la ciudad de Valencia: el Niño Jesús al brazo portando la cruz de los tres clavos, el tallo de lirio o azucena alzado al cielo, los niños inocentes desnudos asomando entre los pliegues del manto que los acoge y cubre, la corona con pedrería y aureola a modo de haz luminoso y los cirios representativos de la cofradía de Santa María de los Inocentes.

Las tres relaciones fueron impresas en tamaño $4^{\circ}$ y poseen un número de páginas múltiplo de cuatro, producto del habitual doblado de uno o dos pliegos sueltos de papel. Carentes de encuadernación original propia, en su momento se incluyeron, junto a otros documentos, en volúmenes facticios. La Segunda Relación, por ejemplo, forma parte de un conjunto de veintiocho textos encuadernados en pergamino bajo el título de Papeles Varios que aparece estampado en su lomo. De otro lado, el elevado precio del papel justifica que el texto poético esté escrito a doble columna en los tres romances con el fin de aprovechar al máximo la caja de escritura y facilitar su imposición y composición. La necesidad de publicar a bajo coste llevaba a eliminar cualquier motivo de ornamento tipográfico que cumpliera la función de separar ambas columnas, a reducir el cuerpo de la letra, a evitar los reclamos, a terminar con finales abruptos (la palabra Fin bajo el último verso, en los tres casos) y a incluir pies de imprenta muy concisos en el colofón (Con licencia, impresso en Valencia, en la Segunda Relación). Estamos, literalmente, ante un producto barato destinado a la venta inmediata entre amplios sectores de la población.

\footnotetext{
4 Cartas a D. Gregorio Mayans. Colegio del Corpus Christi (Valencia), Biblioteca Hispano-Mayansiana, $n^{\circ} 2,25$ de septiembre de 1731

5 Cartas..., 26 de septiembre de 1731

6 Cartas..., 2 de octubre de 1731.

7 La imprenta de la familia García, creada en 1703, había ocupado anteriormente dos locales sucesivos situados junto a la iglesia de San Salvador y enfrente del edificio de la Diputación.

8 En algunos repertorios bibliográficos se dice que el Verdadero Resumen de Pascual Vergadà salió de la imprenta de José Tomás Lucas. Esta afirmación es más que dudosa, dado que este impresor murciano no tuvo oficina en Valencia hasta 1736.
} 


\subsubsection{Contenido}

Según una convicción extendida entre los investigadores, las relaciones de sucesos participaban del proceso de homogeneización ideológica vigente en su época mediante la transmisión de un modelo de sociedad muy conservador. Con este fin, en ellas es frecuente encontrar dedicatorias y elogios de todo tipo hacia las autoridades civiles y eclesiásticas que habían actuado en el restablecimiento del orden durante y después de la catástrofe. Más allá del natural interés de sus autores por mantener buenas relaciones con el poder establecido, este hecho plantea el interrogante de si no serían estas mismas autoridades las que estarían detrás de la publicación de unos textos (anónimos) a los que la censura trataba de una manera muy benévola antes de otorgar rápidamente la licencia preceptiva. Estaríamos, en este caso, ante un ejemplo claro de cómo se manipulaba a la opinión pública aprovechando la enorme difusión de las relaciones y su vinculación con el horizonte de espera de la mayoría de la población. A pesar de su apariencia simple y directa, estos relatos actuarían como emisores interesados de la realidad oficial y serían un mecanismo muy útil para la consolidación de las instituciones.

El contenido de nuestros poemas confirma esta sospecha. Dos de ellos, el Verdadero Resumen y la Verdadera Relación, parecen próximos al entorno del capitán general de Valencia, el príncipe de Campoflorido, mientras que el tercero, la Segunda Relación, está vinculado directamente a las autoridades civiles del municipio, con Blas Jover a la cabeza. Todo hace pensar que estamos ante una disputa soterrada entre los distintos poderes de la ciudad para conseguir la adhesión popular a su causa, en un contexto marcado por los relativamente cercanos decretos de Nueva Planta y la pérdida de los derechos forales. Después de una lectura atenta, no me cabe la menor duda de que, tras conocer los dos primeros romances (los "romanzotes groseros" que envió a Mayans), fue la ausencia de cualquier referencia a la intervención de los técnicos municipales y a la suya propia durante la tragedia la que hizo que Jover encargase la redacción del tercero (que, por este motivo, es algo posterior) y, al tiempo, se dirigiese al impresor Antonio Bordázar con la esperanza de que encontrase una solución intermedia que limase las asperezas políticas.

En los primeros romances citados los elogios hacia la figura de Catalina de Gravina, esposa del capitán general, rozan la pleitesía. Según se dice en ellos, en ausencia de su marido, esta nueva Judith se hizo cargo de la toma de decisiones y movilizó a las tropas acuarteladas en el palacio del Real para desalojar a los curiosos que ocupaban los puentes y los pretiles próximos, vaciar los sótanos y la planta baja del edificio de animales y carruajes, y ordenar su traslado al interior del casco urbano para salvaguardarlos. Además, en este nuevo episodio de su lucha contra Holofernes (el río Turia) hizo exponer el Santísimo Sacramento de la capilla del palacio en uno de sus balcones y desde él se dirigió a sus subordinados como un renacido San Pablo. A lo largo de los dos textos se le califica como excelentísima, princesa, heroica, musa, virtuosa, compasiva, discreta, etc. y se le atribuye la salvación de cientos de personas. En el tercer romance, en cambio, el protagonismo recae directamente en Blas Jover, a quien se presenta como el principal responsable de las soluciones adoptadas en los momentos más críticos de la inundación. Fueron su industria, vigilancia, compasión, celo amante, etc. los que le permitieron aminorar los daños en la ciudad en estrecha colaboración con el corregidor y los regidores del ayuntamiento. Más tarde, advertido de la destrucción causada en otros lugares, recorrió los parajes afectados en compañía de carpinteros y maestros de obras y, "metido entre lodazales", adoptó "todas las diligencias posibles" para su socorro. ${ }^{9}$ En este juego de vanidades, sólo la Iglesia Metropolitana aparece citada con admiración y respeto en los tres poemas.

En la búsqueda de esta caja de resonancia, no había mejor forma literaria que el romance ya que vinculaba las relaciones de sucesos con la gran tradición del romancero popular. La razón hay que buscarla en el hecho de que su estructura, basada en versos de arte menor y rima asonante en los pares, permitía que tanto la composición como la lectura de estas relaciones fueran accesibles a cualquier persona con una mínima instrucción. El empleo de un estilo fácil y ameno, basado en la repetición abusiva de fórmulas, imágenes y rimas, y en registros retóricos que enfatizaban el sensacionalismo, hacía de las relaciones de sucesos un ejemplo de literatura popular (Ettinghausen, 1995). La inmediatez de la tragedia descrita las aproximaba al género epistolar y las alejaba de la crónica, más culta, con la que, sin embargo, compartían el interés por los sucesos con límites cronológicos precisos, el uso de fuentes privilegiadas

9 De manera paralela a lo sucedido en la ciudad de Valencia, en su huerta sur el desbordamiento conjunto del barranco de Torrent y de las numerosas ramblas que drenaban el llano de Quart provocó la destrucción de los lugares de Xirivella, Aldaia y Alaquàs. Hay que recordar aquí que Blas Jover era, además de Alcalde Mayor en la Sala del Crimen de la Real Audiencia de Valencia y de teniente del Consejo de su Majestad, procurador de Alejandro Fernández de Córdoba, duque de Santo Gemini y señor de la villa de Alaquàs. 
(incluyendo el autor-testigo) y la interpretación simultánea al relato. La necesidad de interactuar con el lector-receptor y de despertar su curiosidad por el hecho narrado, así como de explotar el sentimiento colectivo de incertidumbre, les llevaba a adoptar, por último, una estrategia discursiva cercana a la oralidad.

En esta estrategia resultaba básico conseguir que el relato fuera aceptado como verosímil. Como puede verse en nuestros poemas, las argucias en esta dirección comenzaban en el mismo título, donde, junto a calificativos admonitorios referidos a las consecuencias de la catástrofe (estragos, desastre, susto, ruinas, etc.), se afirmaba que la relación era verdadera y se detallaba la fecha concreta del suceso. Seguían luego con un conjunto extenso de marcas de verosimilitud: la localización exacta del percance en calles y barrios, el detalle de lo sucedido en construcciones y edificios representativos que actuaban como hitos urbanos (el azud de Rovella, los puentes sobre el río, las iglesias y conventos, el palacio del Real, los portales de la muralla, etc.), el nombre concreto de los personajes ya citados y, sobre todo, las anécdotas sensacionalistas que debieron correr de boca en boca en los días siguientes a la tragedia. Así, es recurrente la mención a la anciana que estuvo luchando por su vida agarrada a una cuerda junto a la iglesia de Santa Mónica, el cadáver encontrado enterrado en la arena en las proximidades del puente de San José, el grupo de personas que tuvo que pasar la noche aislado en el convento de Santo Domingo o la altura alcanzada por las aguas en el convento de la Trinidad (donde se conservaba una inscripción de la riada de 1517). En este afán de reconocimiento, las relaciones aventuran, incluso, algunos detalles técnicos como los efectos de la angostura del azud de Rovella en la salida de madre de las aguas, los trabajos efectuados de urgencia por los maestros de obras municipales para evacuar el agua acumulada en el interior del casco urbano o el cálculo del caudal emitido por los álveos de evacuación que quedaron por debajo del nivel del río. ${ }^{10}$

Este discurso intradiegético, en el que se simultanea el tiempo de la escritura (la diégesis) y el tiempo del relato (la mímesis), ha sido definido como comparativo o interpretativo analógico, al reunir el fenómeno descrito y la causalidad del mismo en un solo texto (Bégrand, 2003). En él, la causa de la catástrofe siempre se atribuye, en clave alegórica, a un castigo divino y se presenta con un tono apocalíptico cargado de hiperónimos (pecados, vicios, faltas, perfidias, etc.). Este providencialismo responde a una norma cultural muy extendida y sirve para que el autor de la relación se arrogue, finalmente, el papel de portador de un mensaje colectivo: el Dios vengativo, enfurecido e iracundo del Viejo Testamento que ordena la catástrofe también es poseedor de la misericordia que nos libra de ella. El "pecador altivo" que había causado su furia debía rendirse ante la magnitud de su poder, pedirle perdón y confiar en su amor y en su piedad. La riada se convertía, por este camino, en una oportunidad para revisar las conciencias y recuperar la fe perdida. El optimismo final, reforzado por la elogiada intervención de los cargos eclesiásticos durante la tragedia, prestigiaba la obra redentora de la Iglesia y le otorgaba un lugar privilegiado entre las instituciones de la ciudad.

En consonancia con este discurso regenerador, la decisión última se atribuye, en los tres poemas, a la intercesión piadosa de la Virgen de los Desamparados. La devoción popular hacia ella, nacida en el siglo $\mathrm{XV}$, se generalizó tras la epidemia de peste de 1646, cuando, tras la curación del conde de Oropesa, virrey de la época, se le atribuyó el fin de la enfermedad y fue consagrada como patrona de la ciudad y del reino de Valencia. Las invocaciones son especialmente significativas en su caso. La Virgen es convocada repetidamente mediante el Ave Maris Stella, himno mariano del siglo IX, y su nombre va acompañado de todo tipo de calificativos admirativos: abogada precisa, amparadora propicia, segura guía, soberana reina, reina de los cielos, etc. El objetivo de esta invocación no era otro que conseguir que la Virgen, tras hablar con su hijo, "aplacase la ira divina, contuviese furias y detuviese el brazo de la omnipotencia divina".

En esta narración destaca, finalmente, el empleo de recursos como la estructura de tema constante, los mecanismos cohesivos con función anafórica (o encapsuladores), la metáfora sistemática y la humanización de los elementos naturales del relato. En el caso de nuestros tres romances la escritura es lineal y repetitiva en extremo, dado que sigue la trayectoria de las aguas y se detiene constantemente en los efectos de su impacto en edificios y obras. La ilación de los distintos episodios se consigue por medio de la elipsis, las repeticiones literales y el uso de sintagmas nominales, sinónimos y pronombres en el inicio de los hemistiquios del romance. La antropomorfización del río Turia, al que se presenta como codicioso, altivo, arrogante, insaciable, etc., esclavo de su voraz hidropesía y capaz de tomar decisiones propias (hacer alarde de sus conquistas, apoderarse de los campos, templar la sed de su codicia, etc.), no impide que también

10 Doce muelas en el portal del Cid, según Vergadà. En el antiguo reino de Valencia la muela equivalía a 12 pies cúbicos castellanos por minuto. Un pie castellano eran, aproximadamente, 0,278 metros. 
se le confunda con un monstruo al que acompañan "víboras, serpientes, culebras y otras iniquias bestias". El uso de la metáfora alcanza su cénit en la Verdadera Relación, donde el Turia es el "Capitán de la fluitiva Milicia de las armas de Neptuno" y toda su actuación es descrita en términos castrenses: tren de artillería, trincheras, baterías, cañones de cristal, balas de espuma, etc. Las nubes son tropas auxiliares; las ramblas y barrancos, batidores y huestes; los edificios, castillos asaltados, asediados; los muertos, en fin, prisioneros a los que no se da quartel.

\subsection{La "Puntual Relación" de Antonio Bordázar}

Antonio Bordázar (Valencia, 1671-1744) fue uno de los principales activos de la vida cultural en la ciudad de Valencia durante la primera mitad del siglo XVIII (Ximeno, 1747-1748: II, 275-280). Hijo del impresor Jaime Bordázar, realizó su primera impresión en solitario en 1701 y heredó el taller familiar, situado en la plaza del Palacio Arzobispal, en 1707. Impresor oficial de la Ciudad y del Santo Oficio de la Inquisición, desarrolló de manera paralela una importante labor intelectual que le llevó a formar parte, siquiera en un segundo plano, del movimiento novator valenciano. Componente habitual de las tertulias científicas que proliferaron en la ciudad durante esos años (en el palacio del marqués de Villatorcas, en la celda de Tomás Vicente Tosca en la congregación de San Felipe Neri o en la casa de Baltasar Íñigo), entabló amistad con los principales miembros de dicho movimiento y les ayudó a publicar sus obras más representativas (la Arithmetica de Juan Bautista Corachán, 1699; el Compendio Mathematico del padre Tosca, 1707-1715). Más tarde, mantuvo una relación semejante con Gregorio Mayans. Bordázar siempre se dirigió a él con respeto en busca de consejo en cuestiones filológicas y no dudó en pedirle que respaldase personalmente sus proyectos más ambiciosos (Plantificación de la Imprenta del Rezo Sagrado, 1732; Idea de una Academia Mathematica, 1740).

Siendo importante la obra publicada de Bordázar (Ortografia española, 1730; Proporcion de monedas, pesos y medidas, 1736; Reduccion de monedas antiguas, 1737; Parecer de un matematico valenciano sobre el cometa..., 1744; etc.), no lo es menos la que quedó manuscrita y está depositada actualmente en la Biblioteca Hispano-Mayansiana del Colegio del Corpus Christi en Valencia. Entre otros muchos, en este fondo se encuentran textos tan valiosos como unas Recreaciones Mathematicas en la línea de Jacques Ozanam, un Diccionario Facultativo a modo de enciclopedia omnicomprensiva o unas Tablas Chronologicas Universales con el cálculo improbable de todo lo acontecido. Interesado por la geografía y la cartografía, entendidas como ramas de las ciencias físico-matemáticas, Bordázar fue, además, el encargado de renovar los planos respectivos de la ciudad y de la particular contribución de Valencia de Francisco Antonio Cassaus (1695) y del padre Tosca (1704), en las décadas de 1730 y 1740 (Faus, 1987). No estamos, pues, ante un autor prototípico de relaciones de sucesos. De hecho, la Puntual Relación (1731) puede considerarse una obra menor en la trayectoria de Bordázar, un encargo incómodo atendido de la mejor manera posible en un tiempo récord. ${ }^{11}$

Como se dijo, la redacción de esta obra respondió a una petición expresa de Blas Jover, quien, descontento ante los primeros romances escritos, le pidió a Bordázar, en nombre de "un grupo de amigos", que intentase mejorarlos. A los ojos interesados de Jover no podía haber un candidato más cualificado para cumplir este encargo: Bordázar poseía un sólido prestigio y estaba al tanto de las novedades editoriales aparecidas en la ciudad; conocía a Vergadà, puesto que había publicado una obra suya unos años antes (Folla Real, 1728); tenía la obligación de mantener buenas relaciones con el poder político que representaba Jover porque de ellas dependía la buena marcha de su imprenta; y, por último, había sido uno de los muchos testigos directos de la inundación. ${ }^{12}$ El impresor cumplió este cometido rápidamente entre el domingo 30 de septiembre y el martes 2 de octubre, fechas que se corresponden con el dato más tardío de los que aparecen en el texto y la que encabeza la carta dirigida a Mayans en la que Bordázar se excusaba por una obra que consideraba impropia del talento de su interlocutor.

La Puntual Relación, escrita en prosa, es un relato de ocho páginas impreso en el taller del propio Bordázar que, en la línea de los anteriores, carece de portada independiente y de cualquier elemento de adorno. Redactado con un estilo suelto y sin apenas elementos retóricos, su narración de la avenida se ajusta en gran medida a la existente en el Verdadero Resumen de Pascual Vergadà. De él lo separan, sin em-

11 Un ejemplar de la Puntual Relación de Bordázar puede consultarse en la Biblioteca Valenciana. 12 Cartas..., 19 de septiembre de 1731. 
bargo, varios aspectos atribuibles a la condición social y profesional de Bordázar y al carácter preilustrado de su obra. Esta relación:

a) Está firmada por su autor, que se desmarca de este modo de la anonimia generalizada en este tipo de textos.

b) Amplia el espectro de los dignatarios políticos a quienes se elogia por su actuación durante la avenida. Además del cabildo eclesiástico, tanto Catalina de Gravina como Blas Jover son tratados con la mayor deferencia. Junto a ellos son citados con admiración el vicario general de la diócesis, el corregidor, los alcaldes mayores del municipio y los ministros y magistrados de la Real Audiencia. Constituye, pues, todo un monumento a la diplomacia de salón.

c) Refiere su contenido a un contexto general en el que los sucesos naturales extraordinarios estaban a la orden del día. Según se dice en ella, lejos de ser una excepción, la riada del Turia fue uno de los muchos sucesos naturales que tuvieron lugar en 1731 en el reino de Valencia. ${ }^{13}$ Sabemos, por ejemplo, que en esas mismas fechas se desbordó el río Segura en Orihuela (riada de San Nicomedes) y que faltó poco para que también lo hiciera el río Júcar en la Ribera (Alberola, 2006; 2010; 2014).

d) Cumple rápidamente el trámite del obligado providencialismo y se detiene en la explicación científica de la riada. Así, tras aludir en el primer párrafo a la "justa indignación de Dios N.S." como causa disfórica, atribuye la rapidez de la avenida y sus consecuencias a la lluvia caída en un radio de apenas 10-12 leguas (unos 60 kilómetros) en torno a la ciudad, a la coalescencia de la red de barrancos del llano de Quart y a la incapacidad del cauce artificial del río para vehicular toda el agua que arrastraba a su paso por el casco urbano. ${ }^{14}$ El vocabulario técnico empleado en ella excede en mucho al de los poemas anteriores (paredones, pretiles, álveos, albañales, etc.).

e) Recoge diversos datos económicos que demuestran el interés del impresor por el mundo empresarial y por las cuentas del municipio. De un lado, menciona las pérdidas provocadas en los campos de la huerta, los talleres de zurradores de Blanqueries, las tiendas de abacería del camino de Morvedre, la botica del hospital Real y los hornos de olleros de Alaquàs. De otro, alude al coste de los puentes asolados (medio millón -de libras valencianas-) y a las ayudas aprobadas por los cabildos municipal y eclesiástico (2.000 libras valencianas cada uno), y se aventura con una estimación de los daños totales (300.000 ducados).

Frente a las fábulas alegóricas anteriores, la relación de Bordázar, dominada por el carácter sobrio de su prosa, es más terrenal, más austera. Sin olvidar los hitos arquitectónicos que guiaban la narración ni las anécdotas sensacionalistas y los rumores que daban forma al poema de Vergadà, el impresor incluye explicaciones y datos que le alejan sensiblemente de la literatura popular. En un equilibrio difícil e inestable, la interpretación teleológica de los hechos pugna en esta obra con el deseo de comunicar la noticia de manera exhaustiva y rigurosa, sin alardes innecesarios. En todo el relato sólo se apela en dos ocasiones a la voluntad de Dios y no existe en él un final optimista que muestre el arrepentimiento de los pecados y la espera de la misericordia divina. En consonancia con el encargo que le dio origen, da la sensación de que estamos ante un informe interno dirigido a las autoridades, ante una carta privada que tuviera a Blas Jover como corresponsal predestinado. Si toda relación de sucesos es heredera de la epístola, la escrita por Bordázar extrema esta condición hasta convertirse en un diálogo directo con su comitente.

\subsection{La "Historia" de Tomás Güell}

Poco es lo que sabemos del dominico Tomás Güell más allá de su condición de bibliotecario y cronista del Real Convento de Predicadores de la ciudad de Valencia. Apenas, que dejó un total de once obras manuscritas y que sus crónicas nos muestran a un agudo observador de la vida que se desarrollaba tanto dentro como fuera de los muros del convento (Fuentes, 1930: 169-175). En una de estas obras, el dietario conservado en la Biblioteca Histórica de la Universidad de Valencia que lleva por título Historia del priorato del P.M. Fr. Miguel Gosalbo, Güell recoge los sucesos acontecidos en su entorno desde octubre de 1728 hasta noviembre de 1731. Se trata de un volumen compuesto por 370 hojas escritas a doble cara,

13 Literalmente, dice: "uno de estos (desastres) le ha cabido à esta Ciudad de Valencia, al mismo tiempo que otras Ciudades, Villas, i Lugares de su Reino han padecido tempestades de rayos, agua, piedra, è inundaciones, con gravissimos daños en los frutos" (p. 1).

14 Bordázar afirma que el cauce apenas pudo dar salida a la mitad del caudal en su cota màxima, a pesar de ser "capaz de llevar diez mil muelas ò filas de agua" (p. 2). 
cada una de las cuales consta de treinta y dos líneas de letra homogénea, notas marginales y reclamos. Las dimensiones del papel son de 0,304 x 0,210 m. y las de la caja de escritura de 0,261 x 0,127 m. La crónica de la riada de 1731 que ahora nos interesa se encuentra entre las páginas 556 y 596 de dicho volumen (entradillas 699 a 755; días 16, 17, 19 y 22 de noviembre).

La suma regularidad de la escritura hace más que evidente que estamos ante un texto puesto en limpio a partir de apuntes previos. De hecho, a lo largo de estas cuarenta páginas coexisten dos narraciones paralelas. De un lado, la reescritura de los acontecimientos recopilados por Vergadà y Bordázar a los que Güell no tuvo acceso directo y afectaban, básicamente, a la margen izquierda del río; ${ }^{15}$ de otro, la relación original de los sucesos que el dominico pudo observar personalmente desde las terrazas y las celdas superiores del convento y en el interior de éste. Si en el primer caso las aportaciones de Güell pueden considerarse casi insignificantes, en el segundo nos encontramos ante la crónica más detallada y vívida de la riada. En ella, nuestro bibliotecario se esfuerza por mostrar el temor inicial desatado entre sus correligionarios, los vecinos del convento y las personas que cruzaban el puente del Real, la forma en que el agua entró en las dependencias monacales y las reacciones inmediatas que se produjeron a su alrededor una vez que la realidad de la avenida fue aceptada por todos. Lo hace con una escritura ágil, desembarazada de cualquier adorno y sólo parcialmente dominada por su condición religiosa.

En esta segunda vertiente del escrito de Güell, la riada se hace más humana. Los "depósitos argilosos" lo impregnan todo hasta dejar memoria duradera de la altura alcanzada por el agua; los monjes corren a los pisos superiores para contemplar (con "anteojos de larga vista") cómo los soldados del palacio del Real desalojan los puentes y pretiles a "bayoneta calada"; los religiosos de los conventos cercanos tocan las campanas "a rebato" en señal de socorro; los huéspedes aislados en el de Santo Domingo, en especial las "inconsolables" madres con hijos menores, tratan de salir de él por todos los medios a su alcance; algunos de los vecinos de la plaza intentan cruzarla con el agua llegándoles "hasta el cuello" o en barcas improvisadas; los políticos municipales se reúnen con los maestros de obras para discurrir las mejores soluciones; etc. Hay, incluso, momentos para el regocijo imprevisto, como cuando Güell afirma que quienes intentaban trasladarse a nado durante la crecida hacían reír a los monjes que los observaban, que se pescó un pequeño barbo en la sacristía de la iglesia o que las mujeres que habían pasado la noche en el monasterio salieron de él "refociladas" tras tomar chocolate en el desayuno. Frente a la sucesión de edificios religiosos anegados de las relaciones anteriores, en estas líneas el protagonismo recae directamente en los actos humanos derivados de la desesperación y la improvisación.

En el desarrollo de este relato, Güell se preocupa de dejar numerosas marcas de verosimilitud. La riada es extraordinaria porque el monje más anciano del convento, de ochenta y cinco años de edad, le dice que no había conocido otra igual; las horas de las oraciones le sirven como marco cronológico de los acontecimientos; describe los hechos en plural mayestático, como corresponde al grupo de observadores del que forma parte (subimos, vimos, veíamos, advertimos, atribuimos, etc.); las pérdidas provocadas en las tiendas del camino de Morvedre las conoce por "un pariente religioso" del dueño de una de ellas; las obras de composición de la plaza de Predicadores de 1689, ahora arrasadas, las contempló cuando "ya tenía más de cuatro años de hábito" en el convento; etc. Junto a estas marcas propias, introduce también las sensacionalistas que toma prestadas de las relaciones anteriores. Así, refiere nuevamente el episodio de la anciana que sobrevivió sujeta a una cuerda en Santa Mónica, la exposición del Sagrario en un balcón del palacio del Real, los temblores provocados en los puentes por el choque de las jácenas de madera que bajaban por el río, la muerte de doscientos carneros encerrados en un corral del camino de Morvedre o el hecho de que una mula entrase en una casa por la ventana del primer piso en este mismo lugar.

Con todo, lo más interesante del texto de Güell es la alternancia continua que se produce en él entre la visión conservadora de un monje sujeto al respeto debido y las opiniones soterradas de un pensador situado a contracorriente. En la primera dirección habría que incluir el enfoque providencialista que le lleva a atribuir el desastre a "la ira de Dios, tan justamente provocada por nuestras culpas", la advocación a San Luis Bertrán y San Vicente Ferrer como protectores del convento o los elogios desmedidos hacia

15 Güell cita a Vergadà y Bordázar en la pág. 590 de su Historia y afirma que las relaciones escritas por ambos se habían adjuntado a los libros 21 y 22 del dietario del Real Convento de Predicadores. No dice nada de las otras dos relaciones en verso estudiadas aquí, lo que parece indicar que tuvieron una difusión mucho menor. 
Catalina de Gravina y las autoridades militares, municipales y eclesiásticas. ${ }^{16}$ En la segunda, una sorprendente ristra de críticas veladas en la que se incluyen:

a) La defensa de las leyes forales. Sin llegar a la reivindicación neoforalista, Güell alude en dos ocasiones a "nuestras leyes" para criticar el vacío legal provocado por los decretos de Nueva Planta. Tras considerar que el origen de este problema cabía situarlo en la entrada de Felipe V en Valencia en 1707, responsabiliza a este vacío de la inundación parcial del casco urbano. En concreto, critica la dejación existente en el control de la actuación de los asentistas de las maderadas que bajaban por el río (para las que había apeaderos en el llano de la Zaidía, entre los puentes de Serranos y la Trinidad y en la Alameda) y la eliminación por cuestiones de seguridad de los montones de tierra situados junto a la barbacana del cauce que siempre habían defendido a la muralla de la ciudad de lluvias y riadas.

b) La reprobación de determinados impuestos reales. Al tratar de las causas secundarias de la inundación, Güell concede gran importancia a la explosión de algunas albercas intraurbanas como consecuencia de la obstrucción de sus conductos de salida con todo tipo de inmundicias. En su opinión, las rejas que cerraban los albañales cumplían una función puramente fiscal, ya que habían sido colocadas para impedir la entrada irregular a través de ellos de mercancías como el tabaco sujetas al pago de arrendamientos al rey. Según sus propias palabras, "por aumentar sus caudales (los arrendadores) exponían á toda la Ciudad, á llorar una lamentable ruina". En contraposición, cuando el corregidor y los regidores municipales decidieron que se retirasen estas rejas para dar salida a las aguas lo hicieron atendiendo al "bien comun y no al lucro del particular".

c) Varias noticias de carácter social. Siendo de quien es, resulta curioso leer en el dietario de Güell ciertas expresiones que podrían entenderse como una suerte de crítica social. Así sucede cuando se hace eco de la venta de la carne de los animales ahogados en el camino de Morvedre al día siguiente de la riada ("los soldados y la gente pobre... llenaron con abundancia ollas y calderos"), cuando se lamenta de que el hospital Real no admitiese a "otros enfermos que soldados", cuando habla de la cena dada en el convento a las personas que debieron pernoctar en él y afirma que los huéspedes de otras órdenes (tres trinitarios y un capuchino) recibieron mejor trato y pudieron degustar "una pitanza buena y copiosa de pescado", además de ser alojados en la enfermería y no en las celdas, o cuando se refiere a un mendigo que se ofrecía a pasar sobre sus hombros a quienes querían cruzar la plaza durante las aguas altas a cambio de una "limosna de seis u ocho dineros".

En consonancia con esta (supuesta) orientación social, en la Historia del dominico los auténticos protagonistas de la riada son los personajes anónimos. Fue el capitán de la guardia del palacio del Real (y no la mujer del capitán general) quien ordenó el desalojo de los curiosos que asistían al aumento de las aguas en el puente próximo; fue el maestro de obras de la ciudad (y no Blas Jover) quien, al frente de una escuadra de peones, dio las providencias necesarias para la ruptura de la barbacana cercana al portal de Serranos para favorecer el desagüe del barrio contiguo; fueron dos hombres desconocidos (y no el corregidor o los regidores municipales) los que construyeron la balsa de maderos con la que pudieron volver a sus casas dieciocho de las personas aisladas en el convento de Santo Domingo; fue, en fin, un grupo de veinte trabajadores (y no la dirección del monasterio) el que, al cabo de tres días, consiguió devolver a su estado habitual el refectorio del Temple. Frente al carácter laudatorio e impersonal de las relaciones de sucesos, impresas y públicas, las memorias manuscritas permiten esta lectura entre líneas, esta búsqueda de intenciones y sentimientos ocultos. Que Güell abriera la crónica de la riada con una alusión al higienismo y el ambientalismo propios del siglo XVIII quizá quiera decir algo. ${ }^{17}$

\subsection{La "Recopilación" de Juan Pahoner}

En la década de 1750, el archivero catedralicio Juan Pahoner volvió a dejar constancia de la inundación del Turia de 1731 en unos apuntes que quedaron manuscritos y fueron reunidos bajo el título de Re-

16 A diferencia de otras relaciones, el dietario de Güell no cita directamente a Blas Jover. Sus elogios hacia las autoridades municipales son genéricos. Los mayores elogios están dedicados al arzobispo de Valencia, de quien se dice que donó 5000 libras de su propio bolsillo para completar las 2000 aprobadas por el cabildo metropolitano.

17 Güell atribuye la riada a las lluvias caídas sobre la ciudad y su entorno en los dos días antecedentes y contrapone este efecto negativo a los beneficios de dichas lluvias sobre la salud. En su opinión, "las lluvias han sido salutiferas para el cuerpo; porque si el Otoño es seco, ocasiona en Valencia muchas enfermedades" (p. 557). 
copilacion de Especies sueltas perdidas. Aunque estos apuntes misceláneos, continuados luego por Manuel Lucía Mazparrota, no son contemporáneos de la riada, hay que concederles la consideración de fuente primaria dado que Pahoner los escribió a partir de la documentación original que tenía a su alcance en el archivo de la Catedral de Valencia (actas capitulares, protocolos, etc.). Hay que recordar a este respecto que Pahoner fue el encargado de ordenar dicha documentación, en calidad de beneficiario auxiliar de los sucesivos canónigos directores, entre 1748 y 1781 (Robres, 1973; Fita, 1995). Las páginas que dedicó a la inundación (un total de dieciséis) se encuentran en dos tomos separados y su redacción parece responder a dos momentos de inspiración distintos. Así se deduce del hecho de que existan datos repetidos en ambas anotaciones o de que una misma información sea dada con parámetros diferentes según el tomo del que se trate. Es lo que sucede, por ejemplo, con la altura alcanzada por las aguas en varios puntos de la ciudad, que es recogida en pies valencianos en uno de los tomos y en varas valencianas en el otro. ${ }^{18}$

Se trata, sin duda, de la noticia más interesante de las aportadas por Pahoner junto con la referida al desbordamiento paralelo del barranco de la Creu de Xàtiva (o de Patraix) al sur del casco urbano, ya que a partir de ella y de los datos desperdigados en los escritos anteriores es posible hacerse una idea de la magnitud de la riada (Cuadro 1). Por lo demás, los apuntes de Pahoner parten de las relaciones de Vergadà y Bordázar para la descripción de la inundación y sólo las completan en algunos aspectos de detalle. Es lo que ocurre con el desarrollo de los acontecimientos en las proximidades del puente de San José y con las deliberaciones del cabildo metropolitano de Valencia. En el primer caso, Pahoner se detiene en la descripción del impacto de la riada en los muros de los huertos de Nicolás Julián, del conde de Parcent, del colegio de San Pablo y de los conventos de la Corona y del Corpus Christi, antes de seguir el curso de las aguas hacia el convento del Carmen y la parroquia de la Santa Cruz. En el segundo, se preocupa de incluir la relación de los comisarios nombrados para el reparto de las ayudas dadas por la iglesia metropolitana, el ayuntamiento de Valencia y, a título particular, el arzobispo Andrés de Orbe y Larrategui.

Cuadro 1. Altura alcanzada por las aguas de la riada del Turia de 1731, según las relaciones y crónicas conocidas del suceso.

\begin{tabular}{|l|l|l|}
\hline \multicolumn{1}{|c|}{ Lugar } & \multicolumn{1}{|c|}{ Localización } & \multicolumn{1}{c|}{ Altura del agua } \\
\hline Barrio de Blanquerías & $\begin{array}{l}\text { Intramuros } \\
\text { Margen derecha }\end{array}$ & 3-4 palmos (0,6-1 metro) \\
\hline Camino de Morvedre & $\begin{array}{l}\text { Extramuros } \\
\text { Margen izquierda }\end{array}$ & 4 palmos (0,9 metros) \\
\hline Monasterio de la Trinidad & $\begin{array}{l}\text { Extramuros } \\
\text { Margen izquierda }\end{array}$ & $8-9$ palmos (1,8-2 metros) \\
\hline Cuartel de Caballería & $\begin{array}{l}\text { Extramuros } \\
\text { Margen izquierda }\end{array}$ & $5-6$ palmos (1,1-1,3 metros) \\
\hline San Pío V & $\begin{array}{l}\text { Extramuros } \\
\text { Margen izquierda }\end{array}$ & $5-6$ palmos (1,1-1,3 metros) \\
\hline Palacio Real & $\begin{array}{l}\text { Extramuros } \\
\text { Margen izquierda }\end{array}$ & 4 palmos (0,9 metros) \\
\hline Convento de Santo Domingo & $\begin{array}{l}\text { Intramuros } \\
\text { Margen derecha }\end{array}$ & $9-10$ palmos (2-2,2 metros) \\
\hline Convento del Remedio & $\begin{array}{l}\text { Extramuros } \\
\text { Margen derecha }\end{array}$ & 9 palmos (2 metros) \\
\hline $\begin{array}{l}\text { Convento de San Juan de } \\
\text { Ribera }\end{array}$ & $\begin{array}{l}\text { Extramuros } \\
\text { Margen izquierda }\end{array}$ & 4 palmos (0,9 metros) \\
\hline Ermita de Montolivet & $\begin{array}{l}\text { Extramuros } \\
\text { Margen derecha }\end{array}$ & 3 palmos (0,6 metros) \\
\hline
\end{tabular}

Frente a la emotividad sensacionalista (y relamida) de las relaciones en verso de la avenida, la seriedad intelectual con la que Bordázar redactó la suya y el detallismo pormenorizado y crítico del dietario de Güell, la crónica de Pahoner resulta fría, exenta de pasión, como hecha a título de inventario. Aunque desconocemos si Pahoner había vivido la tragedia en directo, todo nos hace pensar que no. Su presencia en el archivo catedralicio sólo está datada a partir de 1748 y ni siquiera sabemos si había nacido en Valencia. Su texto carece de cualquier referencia personal y las anécdotas que introduce como marca de verosi- 
militud son las que pueden encontrarse en cualquiera de las relaciones anteriores. Estamos ante un acto notarial, ante dos extractos de los libros de actas eclesiásticas mínimamente aderezados con las informaciones paralelas recopiladas por Pahoner. Su trascendencia pública fue, en todo caso, mínima. Rodeadas de una multitud de noticias deslavazadas, las correspondientes a la riada de 1731 carecen de cualquier impronta o rasgo diferencial. Son, en definitiva, dos apuntes sin alma perdidos en un océano de papel. ${ }^{19}$

\section{CONCLUSIÓN}

La literatura catastrófica o de la catástrofe engloba documentos de todo tipo, vinculados entre sí por el impacto de la tragedia de origen y la inmediatez de su redacción. Entre ellos se incluyen las relaciones de sucesos y las memorias personales, dos subgéneros que han cobrado un gran protagonismo en los últimos años entre los investigadores. Las obras integradas en el primero suponían la materialización del concepto aristotélico de catarsis y cumplían la función de liberar momentáneamente a los lectores del rigor de las normas sociales vigentes y de aleccionarles en pos de su cumplimiento futuro. La proyección en otras personas de los pecados que habían conducido al castigo divino que representaba el desastre actuaba como válvula de escape de su cargo de conciencia y creaba la tabla rasa que constituía el día después. Las pertenecientes al segundo, menos sujetas al corsé impuesto por la censura eclesiástica y las obligaciones debidas, recogían, por su parte, aspectos que no encajaban en las publicaciones propagandísticas y mostraban pequeñas fisuras a través de las cuales es posible entrever las creencias, las inquietudes y las disconformidades de sus autores.

Ambos subgéneros pueden completar la imagen puramente administrativa, ligada al recuento de daños, que suele acompañar a la descripción de la tragedia. Como hemos podido comprobar en el caso de la inundación del Turia que afectó a la ciudad de Valencia en 1731, estos documentos, tan distintos como complementarios entre sí, permiten ampliar el marco de estudio con la inclusión del entramado cultural, social y político en el que tenía lugar el siniestro. Junto a la obligada descripción de la destrucción causada por la riada en algunos de los edificios más emblemáticos de la ciudad y los cultivos de su huerta, las cuatro relaciones impresas y las dos memorias manuscritas del suceso que hemos analizado muestran de un modo palmario las reacciones primarias de los individuos y las instituciones que se vieron afectadas por el mismo. El intento de manipulación de la opinión pública a través de dichos documentos, el desacerbado elogio hacia sus comitentes, los egos desatados entre los dirigentes, los leves destellos de una crítica larvada o los apuntes científicos semiocultos entre líneas marcadas por una religiosidad asfixiante, son sólo algunos indicios del modo en que el colapso provocado por el desastre sacaba a la luz la imperfección de un sistema tenido por sólido.

\section{REFERENCIAS}

ALBEROLA, A. (1999): Catástrofe, economía y acción política en la Valencia del siglo XVIII. Valencia, Alfons el Magnànim, 333 pp.

ALBEROLA, A. (2006): "Entre la sequía y la inundación. Una aproximación a las avenidas históricas de los ríos valencianos durante el siglo XVIII", en Riesgo de inundaciones en el Mediterráneo occidental, pp. 1-30. Madrid, Casa de Velázquez-Universidad de Alicante.

ALBEROLA, A. (2009a): "De la percepción popular a la reflexión erudita. La transmisión de la cultura de la catástrofe en la España del siglo XVIII", en La réception de la cultura de masses et des cultures populaires en Espagne (XVIIIe-XXe siècles), pp. 39-67. Université de la Sorbonne Nouvelle de Paris.

ALBEROLA, A. (2009b): "La natura desfermada. Al voltant de manuscrits, impresos i imatges sobre desastres naturals en l'Espanya del segle XVIII", en Desastre natural, vida cotidiana y religiosidad popular en la España moderna y contemporánea, pp. 17-76. Universidad de Alicante.

ALBerolA, A. (2010): Quan la pluja no sap ploure. Sequeres i riuades al País Valencià en l'Edat Moderna. Valencia, PUV, 251 pp.

ALBEROLA, A. (2014): Los cambios climáticos. La Pequeña Edad del Hielo en España. Madrid, Cátedra, 341 pp. ALMELA, F. (1957): Las riadas del Turia (1321-1949). Ayuntamiento de Valencia. 129 pp.

19 Las Especies sueltas perdidas de Juan Pahoner y Manuel Lucía Mazparrota ocupan más de once mil páginas en un total de dieciocho volúmenes en folio 
ANÓNIMO (1731): Verdadera Relación alegórica, en metafora de Marte, en que se da cuenta de los estragos, sustos, y ruinas que executò el Rio Turia en esta Ciudad de Valencia, y sus contornos en la avenida de el dia 16 de Setiembre de este año de 1731. Valencia, Imprenta de Joseph Garcia, 8 pp.

ANÓNIMO (1731): Segunda Relación, y romance curioso del lamentable estrago, y fatal ruina que ha causado en Valencia, y su contribución la avenida del rio Turia el dia 16 de Setiembre de 1731. Valencia, s.1., 4 pp.

BEGRAND, P. (2003): "De lo natural a lo sobrenatural: discurso reformador y discurso de cruzada en las relaciones de catástrofes naturales", en Las relaciones de sucesos. Relatos fácticos, oficiales y extraordinarios, pp. 117-134. Université de Franche-Comté.

BERNAL, M. y ESPEJO, C. (2003): "Tres relaciones de sucesos del siglo XVII. Propuesta de recuperación de textos preperiodísticos", en Revista científica de información y comunicación, 1, pp. 133-174. Universidad de Sevilla.

BORDÁZAR, A. (1731): Puntual Relación de la Avenida de el Rio Turia, que baña à esta Ciudad de Valencia, sucedida el dia 16 de Setiembre de 1731. Valencia, Imprenta del autor, 8 pp.

ESCARTÍ, V. J. (1998): Memòria privada: literatura memorialística valenciana del segle XV al XVIII. València, Eliseu Climent. 308 pp.

ETTINGHAUSEN, H. (1995): Noticias del siglo XVII. Relaciones españolas de sucesos naturales y sobrenaturales. Barcelona, Puvill Libros. 68 pp.

FAUS, A. (1987): “Aspectos geográficos en la obra de Antonio Bordázar de Artazu, impresor erudito valenciano del siglo XVIII", en Saitabi. Revista de la Facultad de Geografía e Historia, 37, pp. $267-288$. Universidad de Valencia.

FAUS, A. (1988): "Los terremotos de 1748 en el antiguo Reino de Valencia. Documentos de base y notas para su estudio", en Saitabi. Revista de la Facultad de Geografía e Historia, 38, pp. 203-218. Universidad de Valencia.

FAUS, A. (1999): "La ciudad de Valencia ante las riadas del Turia de 1776", en Cuadernos de Geografía, 65/66, pp. 123-142. Universidad de Valencia.

FITA, R. (1995): "Roc Chabàs i els arxius: notes per al seu estudi”, en Aguaits, 11, pp. 63-80. Dénia, IECMA.

FUENTES. C. (1930): Escritores dominicos del Reino de Valencia. Valencia, Imprenta de F. Ángeles Pitarch. $375 \mathrm{pp}$.

GÜELL, T. (1731): Historia del priorato del P.M. Fr. Miguel Gosalbo, compuesta por Fr. Thomas Guell, Hijo y Bibliotecario de este Santo Convento de Predicadores de Valencia. Empieça Sabado à 16 de Octubre del Año 1728, y fenece en 13 de Noviembre de 1731. Biblioteca Histórica de la Universidad de Valencia, Manuscrito 174.

IGLESIAS, A. (2013): "La interpretación de las catástrofes naturales en el siglo XVII", en Ab Initio, 8, pp. 87-120.

INFANTES, V. (1996): “¿Qué es una relación? (Divagaciones varias sobre una sola divagación)”, en Las relaciones de sucesos en España (1500-1750), pp. 203-212. Universidad de Alcalá-Université de La Sorbonne.

MELIÓ, V. (1991): La Junta de Murs i Valls. Historia de las obras públicas en la Valencia del Antiguo Régimen, siglos XIV-XVIII. Valencia, Consell Valencià de Cultura. 102 pp.

PAHONER, J. (ca. 1751): Recopilacion de Especies sueltas perdidas. Pertenecientes a esta Santa Igl. Metropolitana y a sus Prehimnencias, en donde se hallarán Ordinaciones, Deliberaciones, Privilegios, Bullas, Providencias, Estatutos y diferentes Exemplares del caso. Archivo de la Catedral de Valencia, Manuscritos 377 a 384.

PASTOR, J. (1830): Biblioteca Valenciana de los escritores que florecieron hasta nuestros días y de los que aun viven. Con adiciones y enmiendas á la de D. Vicente Ximeno. Valencia, Imprenta y Librería de Ildefonso Mompié. $356+548$ pp.

PÉREZ, T. y FAUS, A. (1990): "La inundación del Turia de 1731. Narración histórica e interpretación geográfica”, en Quaderns d'Investigació d'Alaquàs, IX, pp. 15-29. Ajuntament d'Alaquàs. 
ROBRES, R. (1973): "La obra inédita del archivero catedralicio Juan Pahoner (1700-1781), Especies Perdidas, y sus continuadores", en I Congreso de Historia del País Valenciano, I, pp. 333-339. Universidad de Valencia.

SERRANO, J. E. (1898-1899): Reseña histórica en forma de diccionario de las imprentas que han existido en Valencia desde la introducción del arte tipográfico en España hasta el año 1868. Valencia, Imprenta de F. Domenech. 655 pp.

SOONS, C.A. (1992): "Una relación de la riada del Guadalquivir de 1618", en Archivo Hispalense, 228, pp. 31-40. Diputación Provincial de Sevilla.

TEIXIDOR, J. (1895): Antigüedades de Valencia, donde con instrumentos auténticos se destruye lo fabuloso, dejando en su debida estabilidad lo bien fundado. Valencia, Imprenta de Francisco Vives Mora, [1757]. $467+504$ pp.

[VERGADÀ, P.] (1731): Verdadero Resumen y compendioso diseño de la memorable avenida de el Turia, principal rio de Valencia: reflujo de sus barrancos, y estragos de sus efectos; en el dia 16 de Setiembre de este presente año 1731. Romance heroico. Valencia, s.l., 16 pp.

XIMENO, V. (1747-1748): Escritores del Reino de Valencia, chronologicamente ordenados desde el año MCCXXXIII de la Christiana Conquista de la misma Ciudad, hasta el d MDCCXLVII. Valencia, Oficina de Joseph Estevan Dolz. $368+385$ pp. 